\title{
The role of somatosensory cortical regions in the processing of painful gastric fundic distension: an update of brain imaging findings
}

L. VAN OUdENHOVE, ${ }^{\star}, \dagger \quad$ P. DUPONT, $\$$ J. VANDENBERGHE,$\dagger$ B. GEERAERTS, ${ }^{*}$ K. VAN LAERE, $\$$ G. BORMANS, $\S$ K. DEMYTTENAERE $\dagger \&$ J. TACK*

*Division of Gastroenterology, Department of Pathophysiology, University Hospital Gasthuisberg, University of Leuven, Leuven, Belgium

$\dagger$ Division of Psychiatry, Department of Neurosciences, University Hospital Gasthuisberg, University of Leuven, Leuven, Belgium ¥Division of Nuclear Medicine, Department of Medical Diagnostic Sciences, University Hospital Gasthuisberg, University of Leuven, Leuven, Belgium

$\S$ Laboratory for Radiopharmacy, Faculty of Pharmaceutical Sciences, University Hospital Gasthuisberg, University of Leuven, Leuven, Belgium

\begin{abstract}
Painful gastric distension is processed in a network consisting of brainstem, thalamus, insula, anterior cingulate cortex, (lateral) orbitofrontal and prefrontal cortex, superior temporal cortex and cerebellum. However, the role of primary and secondary somatosensory cortical regions (SI/SII) in the processing of visceral sensation or pain in general and gastric sensation in particular remains unclear. The aim of this study was to localize activations in the SI/SII area from our previously published functional brain imaging studies on gastric distension more precisely, using newly available cytoarchitectonic probability maps of SI/SII, implemented in the SPM Anatomy toolbox. In healthy volunteers, we found two clusters to be overlapping with SII (mainly the OP4 subregion) and, to a lesser extent, SI, although this overlap was small in size. In functional dyspepsia patients, we found two clusters to be overlapping with SII (mainly OP4), of which the cluster in the right hemisphere also overlapped with SI. These findings were confirmed in a conjunction analysis of both groups. Activation in right SI/SII was significantly higher in healthy volunteers when formally compared to patients. These results provide more detailed information on the brain
\end{abstract}

Address for correspondence

Dr Lukas Van Oudenhove MD, Secretary of Liaison

Psychiatry, University Hospital Gasthuisberg, Herestraat, 49, B-3000 Leuven, Belgium.

Tel: +32 16 3498745; fax: +32 16348700 ;

e-mail: lukas.vanoudenhove@med.kuleuven.be

Received: 10 August 2007

Accepted for publication: 9 October 2007 processing of gastric sensation, supporting the hypothesis that SI/SII are involved. This is in line with some previously published studies on visceral sensation, but at variance with some other studies. Methodological differences between the brain imaging studies on gastric distension may account for these somewhat discrepant findings.

Keywords cytoarchitectonic probability maps, functional brain imaging, gastric fundus distension, somatosensory cortex.

\section{INTRODUCTION}

Results of functional brain imaging studies on gastric fundic distension have generally been fairly reproducible. Evidence is growing that painful gastric fundic distension is processed in a network consisting of brainstem, thalamus, insula, anterior cingulate cortex, (lateral) orbitofrontal and prefrontal cortex, superior temporal cortex and cerebellum. ${ }^{1-3}$

However, the role of primary and secondary somatosensory cortical regions (SI/SII) in the processing of visceral sensation or pain in general and gastric sensation in particular, has been the subject of debate, with conflicting results in different studies. ${ }^{1,4,5}$

Recently, cytoarchitectonic probability maps of SI and SII became available. ${ }^{6-8}$ SII is located on the parietal operculum in humans as well as non-human primates. It contains four cytoarchitectonic areas (OP 1-4), with three somatotopic body representations in OP1, OP3 and OP4. ${ }^{6,8,9}$ Moreover, a new Anatomy 
Toolbox for the statistical parametric mapping (SPM) software package allows combination of these cytoarchitectonic probability maps with functional brain imaging data. ${ }^{10,11}$ Using this methodology, activation in OP4 during painful gastric fundus distension in healthy humans was found in a recent functional magnetic resonance imaging (fMRI) study. ${ }^{1}$

The aim of the present study was to localize activations in the SI/SII area from our previously published $\mathrm{H}_{2}{ }^{15} \mathrm{O}$-positron emission tomography (PET) functional brain imaging studies on gastric distension in healthy volunteers and functional dyspepsia (FD) patients ${ }^{2,12}$ more precisely, using the cytoarchitectonic probability maps of SI and SII, implemented in the SPM Anatomy Toolbox.

\section{MATERIALS AND METHODS}

As the subjects and methods of both our PET studies have been described extensively elsewhere, ${ }^{2,12}$ we will provide a brief summary here.

Brain $\mathrm{H}_{2}{ }^{15} \mathrm{O}$-PET was performed in 11 healthy volunteers ${ }^{2}$ and $13 \mathrm{FD}$ patients ${ }^{12}$ during at least two conditions: no distention (baseline condition) and distention to the individually determined thresholds for unpleasant or painful sensation (maximal distention) as determined in the preceding barostat procedure. One minute after starting intragastric balloon inflation (if applicable), an intravenous injection of $300 \mathrm{MBq} \mathrm{H}_{2}{ }^{15} \mathrm{O}$ was administered over $12 \mathrm{~s}$. There was a 10-min interval between two successive injections. Data acquisition (60 s) began as soon as the intracranial radioactivity count rate increased sharply (i.e. usually about 40-60 s after injection). The intragastric balloon was deflated immediately after completion of the data acquisition.

To combine the data from both studies, the data of the healthy volunteers were reprocessed using SPM2 (statistical parametric mapping 2, Wellcome Department of Cognitive Neurology; http://www.fil.ion.ucl.ac.uk/spm). Briefly, the different preprocessing steps are: correction for small movements, warping to Montreal Neurological Institute (MNI) space (using the PET template provided with SPM2) and smoothing the images with a 3-dimensional isotropic Gaussian kernel of $16 \mathrm{~mm}$ full width at half maximum.

SPM was performed using a brainmask to eliminate extracerebral activity. We re-analyzed the contrast maximal isobaric distension minus baseline in both groups separately. We also did a conjunction analysis to detect activations common to both groups. A formal comparison of both groups was performed by subtracting the distension minus base- line contrast from both groups. Statistical threshold was set at $P_{\text {uncorrected }}<0.001$ (voxel level) in all analyses.

We used the cytoarchitectonic probability maps of SI and SII, implemented in the SPM Anatomy Toolbox, to evaluate the location of the activations more precisely. The development of the cytoarchitectonic probability maps of SI/SII ${ }^{6-8}$ and the SPM Anatomy toolbox for combining these maps with functional neuroimaging data ${ }^{10}$ have been described and validated extensively elsewhere. Therefore, we will focus on the precise localization of the activations in SI/SII in this article, which are of interest for the relatively young field of 'enteric neuroscience. ${ }^{13}$ The toolbox can be downloaded as freeware from http://www.fz-juelich.de/inb/ inb-3//spm_anatomy_toolbox.

\section{RESULTS}

\section{Healthy volunteers}

In healthy volunteers, two clusters that were activated during gastric fundic distension partially overlapped with the cytoarchitectonic definitions of SII and, to a lesser extent, SI (Tables 1 and 2, Figs 1 and 2). More specifically, the cluster in the right hemisphere (394 voxels) showed significant overlap with SII (OP4 and, to a lesser extent, OP1 subregions) and the adjacent part of SI [Brodmann area (BA) 3b and 1]. The left-sided cluster was larger (1319 voxels) and was also found to overlap significantly with SII (OP4 and OP1 subregions) and, to a lesser extent, SI (BA 1 and 2). It should be noted that, besides this overlap with the parietal operculum, a large part of the cluster was located on the frontal operculum (inferior frontal gyrus, pars opercularis).

\section{Functional dyspepsia}

In FD patients, we also found two clusters that were activated during gastric fundic distension to be partially overlapping with SII and, to a lesser extent, SI (Tables 3 and 4, Figs 3 and 4). The right-sided cluster was predominantly located on the frontal operculum, but showed some overlap with SII (OP4) and, although small, with SI (BA 3b). The left-sided cluster was again larger (1954 voxels) and showed more overlap with SII compared with the right-sided cluster.

\section{Conjunction analysis}

In the conjunction analysis, two clusters were found to be partially overlapping with SII and again to a 
Table 1 Clusters showing overlap with primary and/or secondary somatosensory cortex (SI/SII) that are activated during painful gastric fundic distension in 11 healthy volunteers (Ref. 2, reanalyzed with statistical parametric mapping 2)

\begin{tabular}{|c|c|c|c|c|c|c|}
\hline $\begin{array}{l}\text { MNI-coordinate of } \\
\text { local maximum } \\
(x, y, z \text { in } \mathrm{mm})\end{array}$ & $\begin{array}{l}P_{\text {FWE-corrected }} \\
\text { (voxel level) }\end{array}$ & $\begin{array}{l}P_{\text {FDR-corrected }} \\
\text { (voxel level) }\end{array}$ & $\begin{array}{l}t \text {-value } \\
\text { (voxel } \\
\text { level) }\end{array}$ & Tentative anatomical localization & $\begin{array}{l}\text { No. voxels } \\
\text { in cluster }\end{array}$ & $\begin{array}{l}P_{\text {corrected }} \\
\text { (cluster } \\
\text { level) }\end{array}$ \\
\hline $68,2,8$ & $<0.001$ & $<0.001$ & 6.30 & Right parietal operculum (OP4) & 394 & 0.148 \\
\hline $70,-12,12$ & 0.79 & 0.05 & 3.41 & Right parietal operculum (OP4 > OP1) & & \\
\hline$-66,-4,14$ & 0.004 & 0.001 & 5.20 & $\begin{array}{l}\text { Left postcentral gyrus (parietal } \\
\text { operculum) (OP4) }\end{array}$ & 1319 & 0.004 \\
\hline$-64,2,8$ & 0.006 & 0.001 & 5.13 & Left parietal operculum (OP4) & & \\
\hline$-62,8,4$ & 0.025 & 0.004 & 4.75 & $\begin{array}{l}\text { Left frontoparietal operculum } \\
\text { (BA } 44 / 45>\text { OP4) }\end{array}$ & & \\
\hline$-68,-18,14$ & 0.123 & 0.007 & 4.26 & $\begin{array}{l}\text { Left parietal operculum } \\
\text { (OP1 > OP4) }\end{array}$ & & \\
\hline$-66,-14,34$ & 0.165 & 0.009 & 4.16 & $\begin{array}{l}\text { Left postcentral gyrus } \\
\text { (parietal operculum) }(\text { BA } 1 / 2>\text { OP4) }\end{array}$ & & \\
\hline
\end{tabular}

Only local maxima located in SI/SII are shown. MNI, Montreal Neurological Institute; FWE, family-wise error; FDR, false discovery rate; BA, Brodmann area; OP1-4, subregions of the parietal operculum (secondary somatosensory cortex, SII).

Table 2 Overlap between clusters significantly activated during painful gastric fundic distension and cytoarchitectonic areas, in healthy volunteers (Ref. 2, reanalyzed with statistical parametric mapping 2)

\begin{tabular}{|c|c|c|c|c|}
\hline $\begin{array}{l}\text { No. voxels } \\
\text { in cluster }\end{array}$ & $\begin{array}{l}\text { Tentative } \\
\text { macroanatomical } \\
\text { localization }\end{array}$ & $\begin{array}{l}\text { Cytoarchitectonic } \\
\text { area }\end{array}$ & $\begin{array}{l}\text { Amount of } \\
\text { cluster within } \\
\text { cytoarchitectonic } \\
\text { area }(\%)\end{array}$ & $\begin{array}{l}\text { Volume of } \\
\text { cytoarchitectonic } \\
\text { area activated }(\%)\end{array}$ \\
\hline \multirow[t]{4}{*}{394} & \multirow[t]{3}{*}{ Right parietal operculum } & Right OP4 & 20 & 14.1 \\
\hline & & Right BA 3b & 10 & 3.8 \\
\hline & & Right BA 1 & 8.7 & 3.9 \\
\hline & Right frontal operculum & Right BA 44 & 20.1 & 8.6 \\
\hline \multirow[t]{4}{*}{1319} & \multirow[t]{2}{*}{ Left parietal operculum } & Left OP4 & 12.2 & 25.5 \\
\hline & & Left BA 1 & 2.9 & 3.7 \\
\hline & \multirow[t]{2}{*}{ Left frontal operculum } & Left BA 44 & 6.9 & 7.6 \\
\hline & & left BA 45 & 3.1 & 4.4 \\
\hline
\end{tabular}

BA, Brodmann area; OP1-4, subregions of the parietal operculum (secondary somatosensory cortex, SII).

lesser extent with SI (Tables 5 and 6). The large cluster in the right hemisphere (2550 voxels) was located on the frontal and parietal operculum as well as in the underlying insula, orbitofrontal cortex, superior temporal gyrus and temporal pole. The cluster showed some overlap with SII, more particularly the OP3 and OP4 subregions. The cluster in the left hemisphere was somewhat smaller (1701 voxels) and also located on the frontal and parietal operculum as well as in the underlying insula and temporal pole. It was found to be substantially overlapping with SII (OP4) and, to a lesser extent with SI (BA 1). It should be noted that the cluster in the left hemisphere, although smaller, showed more overlap with SI/SII. Moreover, the local maxima in this cluster reached a much higher level of signifi- cance, compared with the local maxima in the right cluster (Tables 5 and 6).

\section{Comparison of healthy volunteers and functional dyspepsia patients}

No clusters overlapping with SII or SI were found to show significantly higher activation in patients compared to healthy volunteers. However, a cluster $(774$ voxels) located in right SII/SI was significantly more activated in healthy controls compared to patients. $29.2 \%$ of this cluster was located in OP4 $(41.7 \%$ of OP4 activated) and $11.3 \%$ of the cluster overlapped with OP1 (15.7\% of OP1 activated). Furthermore, $9.3 \%$ of this cluster overlapped with BA $1 \quad 8.3 \%$ of BA 1 activated), whereas $1.5 \%$ of the cluster was located in 


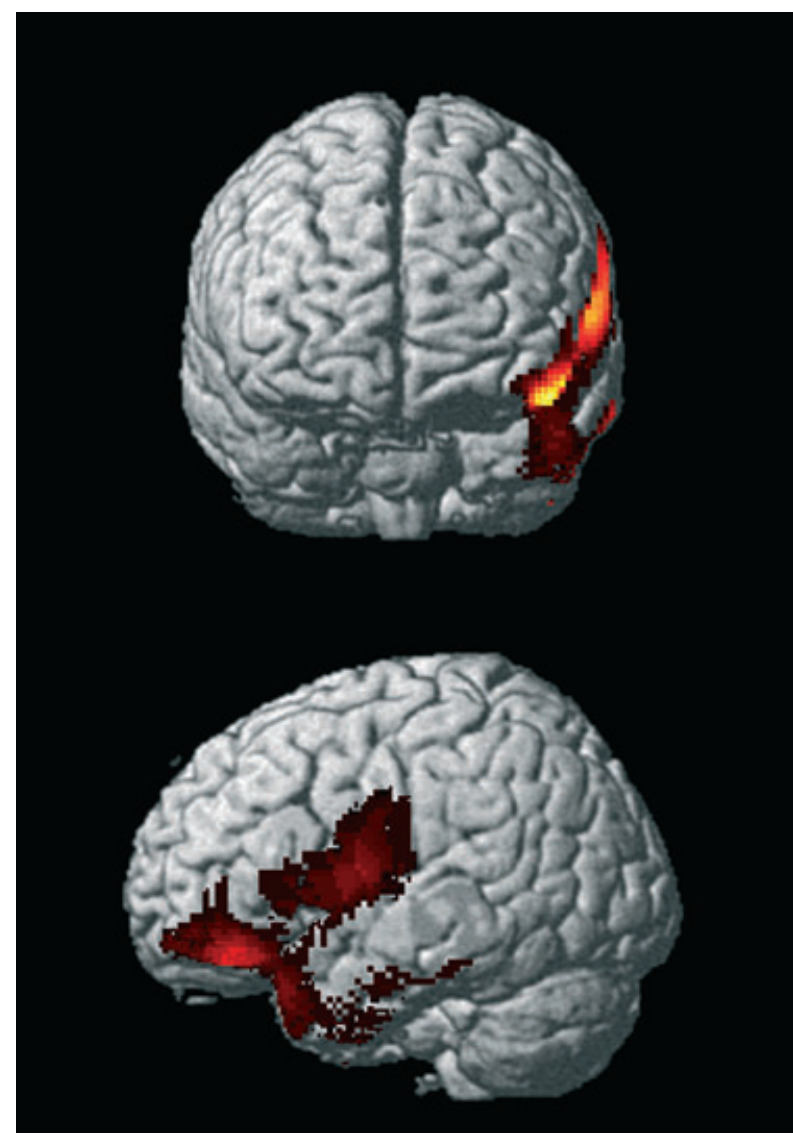

Figure 1 Overview of cluster activated during painful gastric distension in 11 healthy volunteers. Cluster corresponds with the second cluster in Tables 1 and 2.

BA $3 \mathrm{~b}$ (corresponding with $1.2 \%$ activation of this area).

\section{DISCUSSION}

In the present study, we used the cytoarchitectonic probability maps of SI and SII, implemented in the SPM Anatomy Toolbox, to localize activations in the SI/SII area from our previously published $\mathrm{H}_{2}{ }^{15} \mathrm{O}$-PET functional brain imaging studies on gastric distension in healthy volunteers and FD patients ${ }^{2,12}$ more precisely. We also performed a conjunction analysis to detect activations common to both groups as well as a formal comparison of both groups.

Figure 2 Detailed view of cluster activated during painful gastric distension in 11 healthy volunteers. Cluster corresponds with the second cluster in Tables 1 and 2, extent 1319 voxels. Crosshairs at first local maximum (Table 1, MNIcoordinates: $x=-66, y=-4, z=14)$, left postcentral gyrus, assigned to OP4, probability: $40 \%$. Panel 2A: $z=14$, panel $2 \mathrm{~B}$ : $z=6$, panel 2C: $z=22$.
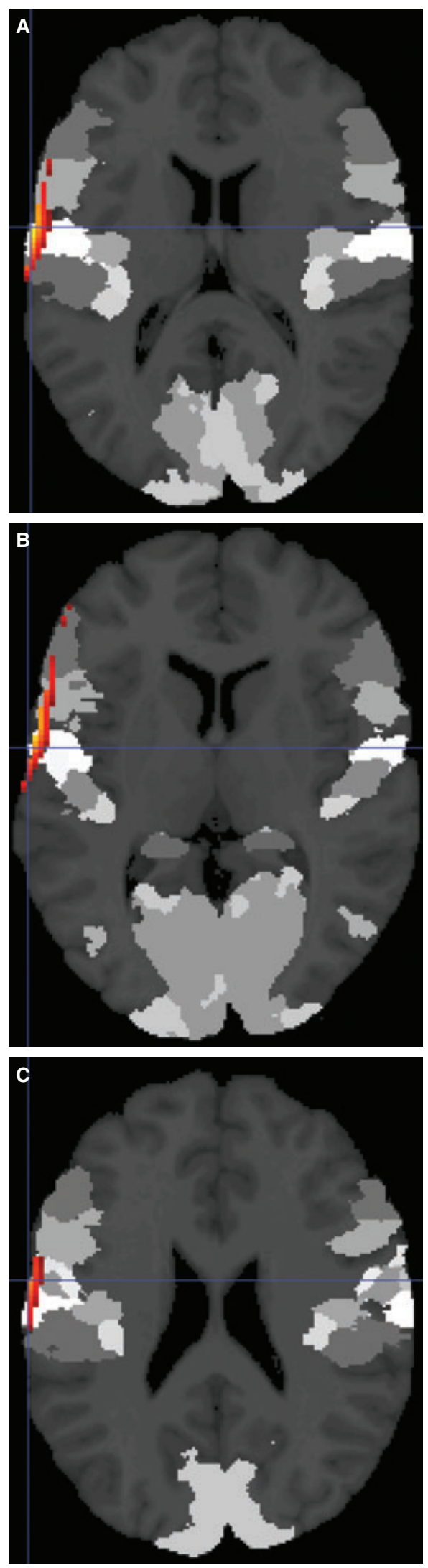

(c) 2007 The Authors 
Table 3 Clusters showing overlap with primary and/or secondary somatosensory cortex (SI/SII) that are activated during painful gastric fundic distension in functional dyspepsia patients with hypersensitivity to gastric distension ${ }^{12}$

\begin{tabular}{|c|c|c|c|c|c|c|}
\hline $\begin{array}{l}\text { MNI-coordinate } \\
\text { of local maximum } \\
(x, y, z \text { in } \mathrm{mm})\end{array}$ & $\begin{array}{l}P_{\text {FWE-corrected }} \\
\text { (voxel level) }\end{array}$ & $\begin{array}{l}P_{\text {FDR-corrected }} \\
\text { (voxel level) }\end{array}$ & $\begin{array}{l}t \text {-value } \\
\text { (voxel } \\
\text { level) }\end{array}$ & Tentative anatomical localization & $\begin{array}{l}\text { No. voxels } \\
\text { in cluster }\end{array}$ & $\begin{array}{l}P_{\text {corrected }} \\
\text { (cluster } \\
\text { level) }\end{array}$ \\
\hline $68,2,12$ & 0.006 & $<0.001$ & 5.29 & Right parietal operculum (OP4) & 812 & 0.01 \\
\hline $66,8,4$ & 0.018 & $<0.001$ & 4.95 & $\begin{array}{l}\text { Right frontoparietal operculum } \\
\text { (BA } 44 \text { > OP4) }\end{array}$ & & \\
\hline$-66,-6,18$ & 0.003 & $<0.001$ & 5.45 & $\begin{array}{l}\text { Left postcentral gyrus (parietal } \\
\text { operculum) (OP4 > BA 3b) }\end{array}$ & 1954 & $<0.001$ \\
\hline$-64,4,24$ & 0.008 & $<0.001$ & 5.17 & $\begin{array}{l}\text { Left frontoparietal operculum } \\
(\text { BA } 6,44>3 \text { b) }\end{array}$ & & \\
\hline$-62,8,2$ & 0.017 & $<0.001$ & 4.96 & $\begin{array}{l}\text { Left frontoparietal operculum } \\
\text { (BA } 44,45>\text { OP4) }\end{array}$ & & \\
\hline$-64,2,8$ & 0.037 & 0.001 & 4.74 & Left parietal operculum (OP4) & & \\
\hline
\end{tabular}

Only local maxima located in SI/SII are shown. MNI, Montreal Neurological Institute; FWE, family-wise error; FDR, false discovery rate; BA, Brodmann area; OP1-4, subregions of the parietal operculum (secondary somatosensory cortex, SII).

Table 4 Overlap between clusters significantly activated during painful gastric fundic distension and cytoarchitectonic areas, in hypersensitive functional dyspepsia patients ${ }^{12}$

\begin{tabular}{|c|c|c|c|c|}
\hline $\begin{array}{l}\text { No. voxels } \\
\text { in cluster }\end{array}$ & $\begin{array}{l}\text { Tentative } \\
\text { macroanatomical } \\
\text { localization }\end{array}$ & $\begin{array}{l}\text { Cytoarchitectonic } \\
\text { area }\end{array}$ & $\begin{array}{l}\text { Amount of cluster } \\
\text { within cytoarchitectonic } \\
\text { area }(\%)\end{array}$ & $\begin{array}{l}\text { Volume of } \\
\text { cytoarchitectonic } \\
\text { area activated }(\%)\end{array}$ \\
\hline \multirow[t]{4}{*}{812} & \multirow[t]{2}{*}{ Right parietal operculum } & Right OP4 & 2.6 & 3.8 \\
\hline & & Right BA 3b & 1.2 & 0.9 \\
\hline & \multirow{2}{*}{ Right frontal operculum } & Right BA 45 & 15.6 & 11.2 \\
\hline & & Right BA 44 & 12.1 & 10.8 \\
\hline \multirow{4}{*}{1954} & Left parietal operculum & Left OP4 & 11.2 & 34.5 \\
\hline & \multirow[t]{3}{*}{ Left frontal operculum } & Left BA 44 & 10.8 & 17.6 \\
\hline & & Left BA 45 & 6.0 & 12.7 \\
\hline & & Left BA 6 & 3.1 & 1.3 \\
\hline
\end{tabular}

BA, Brodmann area; OP1-4, subregions of the parietal operculum (secondary somatosensory cortex, SII).

Our current analysis confirms that bilateral activation of SII is found during rather sustained (160-180 s) gastric fundic distension in (both) healthy volunteers and FD patients. Although two clusters overlapped to a variable extent with SII in both study populations, the activation of SII was relatively small and mainly restricted to the OP4 subregion, which is in line with a recent fMRI study by Ladabaum et al., ${ }^{1}$ but different from the fMRI study by Lu et al. ${ }^{3}$ Activation of SII during visceral (versus somatic) sensation is also at variance with a recent study by Eickhoff et al. ${ }^{14}$ showing that visceral sensation in humans (elicited by rectal distension) is processed more anteriorly (on the frontal operculum), compared to somatic sensation (elicited by anal canal distension), which is processed in SII. It should be noted that in the present study, the frontal operculum was found to be more extensively activated during gastric distension than the parietal operculum including SII. 2,12 All clusters showing overlap with SI/SII also overlapped to a variable extent with the frontal operculum (Tables 2, 4 and 6). This study [with the parietal operculum more extensively activated than the frontal operculum in the conjunction analysis (up to $60 \%$ of OP4 activated)], however, provides fairly strong evidence for a role of SII in the processing of painful gastric fundus distension.

We also found one or two clusters to be overlapping with the cytoarchitectonic probability maps of bilateral SI (BA 3b and BA 1) in both our study groups as well as in the conjunction analysis, although the extent of overlap was even smaller than for SII. This result is at variance with both the studies of Ladabaum et al. and Lu et al., ${ }^{1,3}$ but in line with studies on brain processing of (distal) oesophageal sensation. ${ }^{15-17}$ Thus, activation of SI has been found during distension of the proximal gastrointestinal tract (including the 


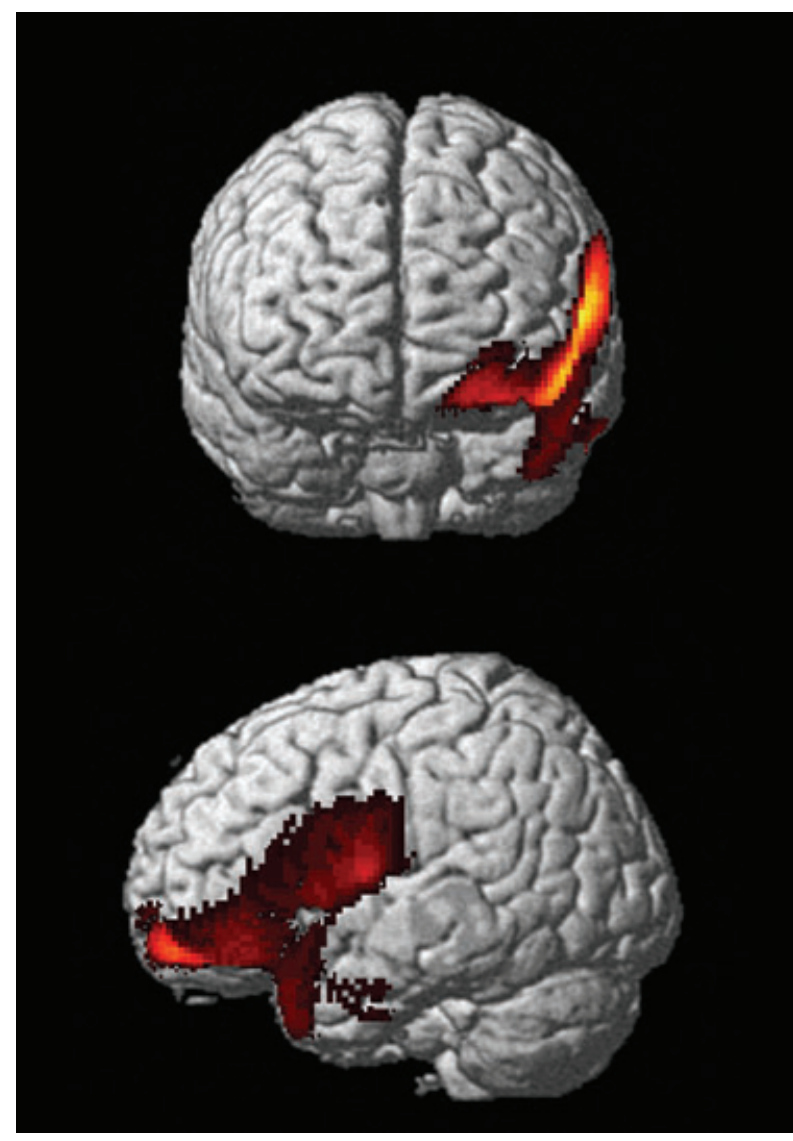

Figure 3 Overview of cluster activated during painful gastric distension in 13 functional dyspepsia patients. Cluster corresponds with the second cluster in Tables 3 and 4.

oesophagus and the proximal stomach), but not in studies on distension of the distal gastrointestinal tract (including the distal stomach and the rectum). ${ }^{18,19}$ Given the small size of this overlap and its proximity to SII in which the largest part of the activated cluster was found, spill-over effects from one region to another cannot be excluded, due to the limited spatial resolution in the processed images. Therefore, these data alone cannot be considered to provide the definite answer on the role of SI in the processing of gastric sensation and pain.

Somewhat surprisingly, a cluster located in right SI/SII showed significantly higher activation in

Figure 4 Detailed view of cluster activated during painful gastric distension in 13 functional dyspepsia patients. Cluster corresponds with the second cluster in Tables 3 and 4, extent 1954 voxels. Crosshairs at first local maximum (Table 3; MNI-coordinates: $x=-66, y=-6, z=18$ ), left postcentral gyrus, assigned to OP4, probability: $40 \%$, probability for BA 3b: 30\%. Panel 4A: $z=18$, panel 4B: $z=10$, panel 4C: $z=26$.
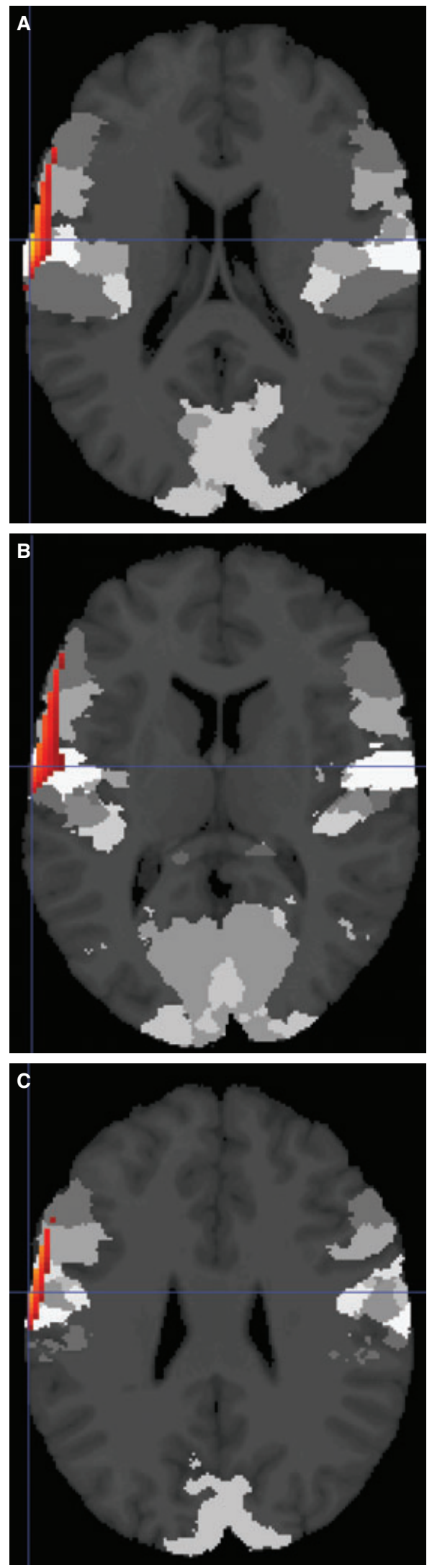

(c) 2007 The Authors 
Table 5 Clusters showing overlap with primary and/or secondary somatosensory cortex (SI/SII) that are activated during painful gastric fundic distension in healthy volunteers and functional dyspepsia patients (conjunction analysis)

\begin{tabular}{|c|c|c|c|c|c|c|}
\hline $\begin{array}{l}\text { MNI-coordinate of } \\
\text { local maximum } \\
(x, y, z \text { in } \mathrm{mm})\end{array}$ & $\begin{array}{l}P_{\text {FWE-corrected }} \\
\text { (voxel level) }\end{array}$ & $\begin{array}{l}P_{\text {FDR-corrected }} \\
\text { (voxel level) }\end{array}$ & $\begin{array}{l}t \text {-value } \\
\text { (voxel } \\
\text { level) }\end{array}$ & Tentative anatomical localization & $\begin{array}{l}\text { No. voxels in } \\
\text { cluster }\end{array}$ & $\begin{array}{l}P_{\text {corrected }} \\
\text { (cluster } \\
\text { level) }\end{array}$ \\
\hline $66,4,12$ & 0.024 & $<0.001$ & 3.12 & $\begin{array}{l}\text { Right frontoparietal operculum } \\
(44>\text { OP } 4>6)\end{array}$ & 2550 & NA \\
\hline $68,-6,12$ & 0.566 & 0.006 & 2.40 & Right parietal operculum (OP4 > >3b) & & \\
\hline $32,-16,12$ & 0.402 & 0.004 & 2.51 & Right parietal operculum (OP2 > OP3) & & \\
\hline $42,-14,24$ & 0.547 & 0.005 & 2.42 & Right parietal operculum (OP3) & & \\
\hline $40,-4,6$ & 0.826 & 0.01 & 2.16 & Right insula (>OP3) & & \\
\hline$-66,-4,18$ & $<0.001$ & $<0.001$ & 4.84 & Left postcentral gyrus (OP4) & 1701 & NA \\
\hline$-66,-8,30$ & $<0.001$ & $<0.001$ & 4.14 & Left frontoparietal operculum (BA $6>1,3 \mathrm{~b}$ ) & & \\
\hline$-62,6,6$ & $<0.001$ & $<0.001$ & 4.51 & Left frontoparietal operculum (BA $44>$ OP4) & & \\
\hline$-64,2,8$ & $<0.001$ & $<0.001$ & 4.60 & Left parietal operculum (OP4) & & \\
\hline
\end{tabular}

Only local maxima located in SI/SII are shown. MNI, Montreal Neurological Institute; FWE, family-wise error; FDR, false discovery rate; BA, Brodmann area; OP1-4, subregions of the parietal operculum (secondary somatosensory cortex, SII); NA, not available in conjunction analysis.

Table 6 Overlap between clusters significantly activated during painful gastric fundic distension and cytoarchitectonic areas, in healthy volunteers and functional dyspepsia patients (conjunction analysis)

\begin{tabular}{|c|c|c|c|c|}
\hline $\begin{array}{l}\text { No. voxels in } \\
\text { cluster }\end{array}$ & $\begin{array}{l}\text { Tentative } \\
\text { macroanatomical } \\
\text { localization }\end{array}$ & $\begin{array}{l}\text { Cytoarchitectonic } \\
\text { area }\end{array}$ & $\begin{array}{l}\text { Amount of cluster } \\
\text { within cytoarchitectonic } \\
\text { area }(\%)\end{array}$ & $\begin{array}{l}\text { Volume of } \\
\text { cytoarchitectonic } \\
\text { area activated }(\%)\end{array}$ \\
\hline \multirow[t]{4}{*}{2550} & \multirow[t]{2}{*}{ Right parietal operculum } & Right OP3 & 3.6 & 34.7 \\
\hline & & Right OP4 & 1.5 & 6.6 \\
\hline & \multirow[t]{2}{*}{ Right frontal operculum } & Right BA 44 & 3.2 & 8.8 \\
\hline & & Right BA 45 & 4.5 & 10.1 \\
\hline \multirow{4}{*}{1701} & \multirow{2}{*}{ Left parietal operculum } & Left OP4 & 23.4 & 61.7 \\
\hline & & Left BA 1 & 4.4 & 7.1 \\
\hline & \multirow[t]{2}{*}{ Left frontal operculum } & Left BA 44 & 5.9 & 8.3 \\
\hline & & Left BA 6 & 4.3 & 1.6 \\
\hline
\end{tabular}

BA, Brodmann area; OP1-4, subregions of the parietal operculum (secondary somatosensory cortex, SII).

healthy volunteers compared to patients. It should be noted, however, that intragastric pressures and volumes were significantly higher in healthy volunteers than those in patients (for equal discomfort scores). Higher activation in SI/SII in healthy volunteers may therefore be consistent with higher visceral afferent input to the brain and the well-established role of SI/ SII in the sensory-discriminative dimension of pain.

Although results of brain imaging studies on gastric sensation and pain are generally converging, subtle differences between studies may account for the differential activation in SI/SII. Firstly, gender differences exist. Ladabaum et al. and Lu et al. ${ }^{1,3}$ studied a predominantly male study population, whereas our groups were predominantly female. As functional gastrointestinal disorders are far more common in women, ${ }^{20}$ and as gender influences regional brain activation during gastrointestinal dis- tension, ${ }^{21}$ recruiting predominantly female healthy populations for brain imaging studies may be most relevant to understanding these disorders. Secondly, distension paradigms were different. All three studies used isobaric distensions and determined pressure threshold for discomfort [relative to minimal distending pressure (MDP)], prior to scanning, but the mean discomfort threshold was significantly higher in the study by Ladabaum et al. ${ }^{1}$ It may be, however, difficult to compare discomfort thresholds between studies as fMRI implicates the need for lengthening the tube from the barostat to the balloon, which has been shown to influence pressure thresholds. ${ }^{22}$ More importantly, the duration and timing of the stimuli was different, due to the difference in temporal resolution between PET and fMRI. Both fMRI studies used block designs in which 40-45 s painful distension blocks were alternating with baseline (MDP) 
blocks of equal duration. In our PET study, more sustained painful distension was applied (160-180 s), with $10 \mathrm{~min}$ between conditions. This may be especially relevant to differences in activation of SI/SII, as this region has been implicated in intensity coding. ${ }^{23}$ Moreover, temporal summation is suggested as a determinant of SI activation in somatic pain. ${ }^{23}$ Thirdly, psychological factors including arousal, anxiety and anticipation of aversive visceral stimuli are important in visceral sensation, especially in functional gastrointestinal disorders. ${ }^{24,25}$ These factors are also known to influence somatosensory cortex activation during visceral and somatic pain. ${ }^{26-28}$ Subtle differences in these psychological processes between studies can account for the observed differences.

In conclusion, the results of studies on the neurophysiology of painful gastric fundic distension published to date are rather convergent, pointing towards a 'gastric sensation neuromatrix' consisting of brainstem, thalamus, insula, anterior cingulate cortex, orbito- and prefrontal cortex and superior temporal cortex. Although the role of SI/SII remains controversial, we believe this re-analysis of our previously published PET-data using newly available probablistic cytoarchitectonic maps of the human parietal operculum implemented in the SPM Anatomy Toolbox provides clear evidence in favour of the hypothesis that SII/SI are implicated in the processing of gastric sensation in health and disease.

\section{ACKNOWLEDGMENTS}

This study was funded by a grant from the Research Foundation - Flanders (FWO-Vlaanderen) to Prof. Tack. Dr Van Oudenhove is a Research Fellow and Prof. Tack is a Clinical Researcher of the Research Foundation Flanders. The authors wish to thank Rita Vos for excellent technical support.

\section{REFERENCES}

1 Ladabaum U, Roberts TP, McGonigle DJ. Gastric fundic distension activates fronto-limbic structures but not primary somatosensory cortex: a functional magnetic resonance imaging study. Neurolmage 2007; 34: 724-32.

2 Vandenberghe J, Dupont P, Fischler B, Persoons P, Tack J. Regional brain activation during proximal stomach distention in man: a PET study. Gastroenterology 2005; 128: 564-73.

3 Lu C-L, Wu Y-T, Yeh T-C et al. Neuronal correlates of gastric pain induced by fundus distension: a 3T-fMRI study. Neurogastroenterol Motil 2004; 16: 575-87.

$4 \mathrm{Lu} \mathrm{C}-\mathrm{L}$, Chang F-Y, Hsieh J-C. Is somatosensory cortex activated during proximal stomach stimulation and the role of insula in visceral pain. Gastroenterology 2005; 128: 1529-30.

5 Van Oudenhove L, Dupont P, Vandenberghe J, Geeraerts B, Tack J. Is somatosensory cortex activated during proximal stomach stimulation and the role of insula in visceral pain - reply to Lu et al. Gastroenterology 2005; 128: 1530-1.

6 Eickhoff SB, Schleicher A, Zilles K, Amunts K. The human parietal operculum. I. Cytoarchitectonic mapping of subdivisions. Cereb Cortex 2006; 16: 254-67.

7 Geyer S, Schleicher A, Zilles K. Areas 3a, 3b, and 1 of human primary somatosensory cortex: 1 . Microstructural organization and interindividual variability. NeuroImage 1999; 10: 63-83.

8 Eickhoff SB, Amunts K, Mohlberg H, Zilles K. The human parietal operculum. II. Stereotaxic maps and correlation with functional imaging results. Cereb Cortex 2006; 16: 268-79.

9 Eickhoff SB, Grefkes C, Zilles K, Fink GR. The somatotopic organization of cytoarchitectonic areas on the human parietal operculum. Cereb Cortex 2007; 17: 1800-11.

10 Eickhoff SB, Stephan KE, Mohlberg H et al. A new SPM toolbox for combining probabilistic cytoarchitectonic maps and functional imaging data. NeuroImage 2005; 25: 1325-35.

11 Tzourio-Mazoyer N, Landeau B, Papathanassiou D et al. Automated anatomical labeling of activations in SPM using a macroscopic anatomical parcellation of the MNI MRI single-subject brain. NeuroImage 2002; 15: 273-89.

12 Vandenberghe J, Dupont P, Van Oudenhove L et al. Regional cerebral blood flow during gastric balloon distention in functional dyspepsia. Gastroenterology 2007; 132: 1684-93.

13 Mayer EA. Enteric neuroscience: the dawn of a new discipline. Gastroenterology 2007; 132: 1217-8.

14 Eickhoff SB, Lotze M, Wietek B, Amunts K, Enck P, Zilles K. Segregation of visceral and somatosensory afferents: an fMRI and cytoarchitectonic mapping study. NeuroImage 2006; 31: 1004-14.

15 Strigo IA, Duncan GH, Boivin M, Bushnell MC. Differentiation of visceral and cutaneous pain in the human brain. I Neurophysiol 2003; 89: 3294-303.

16 Aziz Q, Andersson J, Valind S et al. Identification of human brain loci processing esophageal sensation using positron emission tomography. Gastroenterology 1997; 113: 50-9.

17 Aziz Q, Thompson DG, Ng VWK et al. Cortical processing of human somatic and visceral sensation. I Neurosci 2000; 20: 2657-63.

18 Ladabaum U, Minoshima S, Hasler W, Cross D, Chey W, Owyang C. Gastric distention correlates with activation of multiple cortical and subcortical regions. Gastroenterology 2001; 120: 369-76.

19 Mayer EA, Berman S, Suyenobu B et al. Differences in brain responses to visceral pain between patients with irritable bowel syndrome and ulcerative colitis. Pain 2005; 115: 398-409.

20 Mayer EA, Berman S, Chang L, Naliboff BD. Sex-based differences in gastrointestinal pain. Eur I Pain 2004; 8: 451-63.

21 Berman SM, Naliboff BD, Suyenobu B et al. Sex differences in regional brain response to aversive pelvic visceral stimuli. Am I Physiol Regul Integr Comp Physiol 2006; 291: R268-76. 
22 Lawal A, Kern M, Sidhu H, Hofmann C, Shaker R. Novel evidence for hypersensitivity of visceral sensory neural circuitry in irritable bowel syndrome patients. Gastroenterology 2006; 130: 26-33.

23 Peyron R, Laurent B, Garcia-Larrea L. Functional imaging of brain responses to pain. A review and meta-analysis. Neurophysiol Clin 2000; 30: 263-88.

24 Van Oudenhove L, Vandenberghe J, Geeraerts B et al. Relationship between anxiety and gastric sensorimotor function in functional dyspepsia. Psychosom Med 2007; 69: 455-63.

25 Naliboff BD, Munakata J, Fullerton S et al. Evidence for two distinct perceptual alterations in irritable bowel syndrome. Gut 1997; 41: 505-12.
26 Naliboff BD, Mayer EA. Brain imaging in IBS: drawing the line between cognitive and non-cognitive processes. Gastroenterology 2006; 130: 267-70.

27 Porro CA, Cettolo V, Francescato MP, Baraldi P. Functional activity mapping of the mesial hemispheric wall during anticipation of pain. NeuroImage 2003; 19: 173847.

28 Gregory LJ, Yaguez L, Williams SCR et al. Cognitive modulation of the cerebral processing of human oesophageal sensation using functional magnetic resonance imaging. Gut 2003; 52: 1671-7. 